\title{
Furosemide decreases the sensitivity of glucose transport to insulin in skeletal muscle in vitro
}

\author{
George Dimitriadis ${ }^{1,2}$, Brendan Leighton ${ }^{1}$, Mark Parry-Billings ${ }^{1}$, Charalambos Tountas ${ }^{3}$, Sotirios Raptis ${ }^{2}$ \\ and Eric A Newsholme ${ }^{1}$ \\ ${ }^{1}$ Department of Biochemistry, University of Oxford, Oxford, UK, ${ }^{2}$ Second Department of Internal Medicine, Research Institute and Diabetes Center \\ Evangelismos Hospital, Athens University, Athens, Greece and ${ }^{3}$ Second Department of Internal Medicine, Hipokration Hospital, Athens University. \\ Athens, Greece \\ (Correspondence should be addressed to G Dimitriadis, 103-105 Aegeou Pelagous Str., 15342 Agia Paraskevi, Greece)
}

\begin{abstract}
The effects of the diuretic furosemide on the sensitivity of glucose disposal to insulin were investigated in rat soleus muscle in vitro. At basal levels of insulin, the rates of 3-O-methylglucose transport, 2deoxyglucose phosphorylation and lactate formation were not affected significantly by furosemide $(0.5 \mathrm{mmol} / \mathrm{l})$. However, furosemide significantly decreased these rates at physiological and maximal levels of insulin. The contents of 2-deoxyglucose and glucose 6-phosphate in the presence of furosemide were not significantly different from those in control muscles at all levels of insulin studied. It is concluded that furosemide decreases the sensitivity of glucose utilization to insulin in skeletal muscle by directly inhibiting the glucose transport process.
\end{abstract}

European Journal of Endocrinology 139 118-122

\section{Introduction}

Chronic administration of diuretics impairs glucose tolerance, but the mechanisms involved are uncertain $(1-8)$. Although a decrease in the secretion of insulin has been reported $(4,8)$, additional mechanisms may be involved since these drugs cause hyperglycemia in pancreatectomized dogs or alloxan-diabetic mice (9). Skeletal muscle is quantitatively most important for glucose disposal in response to insulin (10). In this tissue, furosemide impairs the sensitivity of glycolysis to insulin (11). Although this may be caused, at least in part, by a decrease in the activity of key glycolytic enzymes (12), the possibility that furosemide inhibits glucose transport has never been examined. This is important since, in skeletal muscle, the stimulation of glucose transport is the main mechanism by which insulin increases the rate of glucose utilization (13). In rat adipocytes, furosemide and hydrochlorothiazide have been shown to blunt insulin-stimulated glucose transport (14). Therefore, the present study was undertaken to examine the effects of furosemide on the sensitivity of glucose transport and metabolism to insulin in rat skeletal muscle. In order to separate any possible effects of furosemide on glucose transport from those on glucose phosphorylation, two glucose analogs were used: 3-O-methylglucose which is transported but not phosphorylated and 2-deoxyglucose which is transported and phosphorylated but not further metabolized.

\section{Materials and methods}

Male Wistar rats (160g, Olac, Bicester, Oxon, UK) were fasted for $12 \mathrm{~h}$ prior to the experiments and killed by cervical dislocation. Biochemicals were obtained from sources given previously $(15,16)$. Furosemide, dimethylsulfoxide and Dowex-2 (chloride form, dry mesh 200-400) were obtained from Sigma Chemicals, Poole, Dorset, UK, 3-O-methyl $\left[{ }^{3} \mathrm{H}\right]-$ glucose and $\left[{ }^{14} \mathrm{C}\right]$ sucrose from Amersham International (Amersham, Bucks, UK), and $\left[\mathrm{U}^{14} \mathrm{C}\right]$ glucose and 2deoxy $\left[{ }^{3} \mathrm{H}\right]$ glucose from DuPont (Stevenage, Herts, UK).

Soleus muscle strips were isolated as described previously (15) and tied at the resting length on stainless steel clips. Muscles were incubated in KrebsRinger bicarbonate buffer $\left(\mathrm{pH} 7.3,37^{\circ} \mathrm{C}\right)$ containing pyruvate, succinate and glutamate $(1 \mathrm{mmol} / \mathrm{l}$ each), $5.5 \mathrm{mmol} / \mathrm{l}$ glucose and defatted BSA $(1.5 \%$, w/v). The medium was gassed with $\mathrm{O}_{2} / \mathrm{CO}_{2}(19: 1)$. After $30 \mathrm{~min}$ preincubation, the muscles were transferred into new flasks with the same buffer without pyruvate, succinate and glutamate but with insulin. After 60 min incubation muscles were removed, blotted and freeze-clamped in liquid $\mathrm{N}_{2}(15,16)$.

Furosemide was dissolved in dimethylsulfoxide and was added into both the preincubation and incubation flasks at a final concentration of $0.5 \mathrm{mmol} / \mathrm{l}$. Dimethylsulfoxide was also added to the control flasks at the same final concentration.

The rate of glycolysis was estimated from that of lactate formation (17). For the estimation of the rate of 

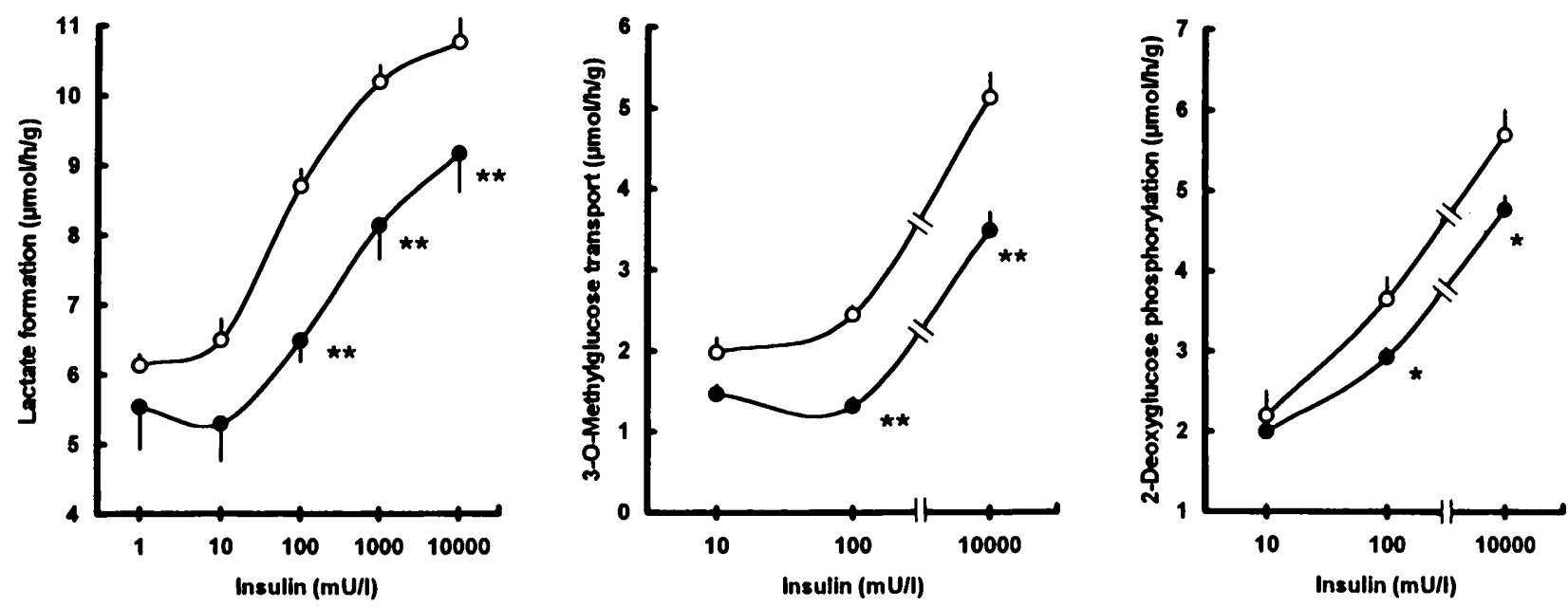

Figure 1 Rates of lactate formation, 3-O-methylglucose transport and 2-deoxyglucose phosphorylation in rat skeletal muscle at various concentrations of insulin in the presence $(\bullet)$ or absence $(O)$ of furosemide $(0.5 \mathrm{mmol} / \mathrm{l})$. Results are presented as means \pm S.E.M. Statistical differences between control and furosemide-treated muscles are indicated by ${ }^{*} P<0.05$ and ${ }^{* \star} P<0.01$.

glucose phosphorylation and the content of nonphosphorylated glucose, trace amounts of 2-deoxy[ $\left.{ }^{3} \mathrm{H}\right]-$ glucose were added to the incubation medium $(0.5 \mu \mathrm{Ci} / \mathrm{ml})$ and muscles were incubated for $60 \mathrm{~min}$ as described earlier in this paper. After incubation, muscles were removed, freeze clamped and powdered at liquid $\mathrm{N}_{2}$ temperature, then homogenized in $6 \%$ perchloric acid and centrifuged to remove precipitated protein. The supernatant was neutralized with $2 \mathrm{~mol} / \mathrm{l} \mathrm{KOH} /$ $0.5 \mathrm{~mol} / \mathrm{l}$ triethanolamine and placed on Dowex-2 (formate-form) ion-exchange columns. The columns were washed first with $20 \mathrm{ml}$ distilled water to elute 2-deoxy $\left[{ }^{3} \mathrm{H}\right]$ glucose and then with $12 \mathrm{ml} 0.3 \mathrm{~mol} / \mathrm{l}$ ammonium formate $/ 1 \mathrm{~mol} / \mathrm{l}$ formic acid to elute 2-deoxy $\left[{ }^{3} \mathrm{H}\right]$ glucose 6 -phosphate (18).

Glucose transport was measured with 3-O-methylglucose. Muscles were incubated in Krebs-Ringer bicarbonate buffer except that D-glucose had been omitted but pyruvate, succinate, glutamate were present $(1 \mathrm{mmol} / \mathrm{l}$ each). After $30 \mathrm{~min}$ muscles were transferred into new flasks with the same buffer containing insulin, 3-Omethylglucose (5.5 mmol/l), 3-O-methyl $\left[^{3} \mathrm{H}\right]$ glucose $(2 \mu \mathrm{Ci} /$ $\mathrm{ml})$ and $\left[\mathrm{U}^{14} \mathrm{C}\right]$ sucrose $(0.1 \mu \mathrm{Ci} / \mathrm{ml})$ and incubated for $10 \mathrm{~min}$. After incubation, muscles were removed, washed in ice-cold Krebs-Ringer bicarbonate buffer, blotted dry and freeze-clamped in liquid $\mathrm{N}_{2}$. Muscles were digested in $1 \mathrm{~mol} / \mathrm{l} \mathrm{KOH}\left(70^{\circ} \mathrm{C}, 30 \mathrm{~min}\right)$ and radioactivity was measured as described previously (19).

The net uptake of 2-deoxy[ $\left[{ }^{3} \mathrm{H}\right]$ glucose and 3-Omethyl $\left[{ }^{3} \mathrm{H}\right]$ glucose into muscles was calculated after correcting for the $\left[{ }^{3} \mathrm{H}\right]$ radioactivity trapped in the extracellular space using the $\left[{ }^{14} \mathrm{C}\right]$ sucrose counts as follows:

$$
\begin{aligned}
{ }^{3} \mathrm{H}_{\text {true }}= & \left({ }^{3} \mathrm{H}_{\text {muscle digest }}\right)-\left(\left[{ }^{3} \mathrm{H} /{ }^{14} \mathrm{C}\right]_{\text {incubation buffer }}\right. \\
& \left.\times{ }^{14} \mathrm{C}_{\text {muscle digest }}\right), \text { where }{ }^{3} \mathrm{H} \text { and }{ }^{14} \mathrm{C} \text { are } \\
& \text { disintegrations per minute. }
\end{aligned}
$$

The content of non-phosphorylated glucose and the rate of glucose phosphorylation were estimated from the radioactivity of the 2-deoxy $\left[{ }^{3} \mathrm{H}\right]$ glucose and 2-deoxy$\left[{ }^{3} \mathrm{H}\right]$ glucose 6-phosphate respectively (19). The rate of 3-O-methyl $\left[{ }^{3} \mathrm{H}\right]$ glucose transport in the soleus muscle is linear for at least $20 \mathrm{~min}$ in the presence of $10000 \mathrm{mU} / \mathrm{l}$ insulin (20). The content of glucose 6-phosphate in the soleus muscle was measured after extraction of the muscles with $6 \%$ perchloric acid as described previously (21).

Results in text and figures (drawn by using Microsoft Excel) are presented as means \pm S.E.M. Statistical analysis of the differences between control muscles and those incubated in the presence of furosemide and of the effects of insulin on these muscles were tested by using two-way ANOVA and non-paired Student's $t$-test.

\section{Results}

The size of the muscle strips used in the experiments was $34 \pm 0.3 \mathrm{mg}$. Previous experiments have established that, at this size, this muscle preparation is in a biochemically viable state for periods of $60-90 \mathrm{~min}$ at $37^{\circ} \mathrm{C}(22)$.

Statistical comparisons of experimental groups (control versus furosemide) by using two-way ANOVA showed that furosemide $(0.5 \mathrm{mmol} / \mathrm{l})$ had statistically significant effects on the overall rates of lactate formation (i.e. glycolysis) $(P<0.01), 3-O$-methylglucose transport $(P<0.01)$ and 2 -deoxyglucose phosphorylation $(P<0.05)$ (Fig. 1). Furosemide had no statistically significant effects on the contents of 2-deoxyglucose and glucose 6-phosphate (Fig. 2). When interactions between experimental groups (control and furosemide) and insulin concentrations were tested, the effectiveness of insulin to increase the rates of 3-O-methylglucose transport and 

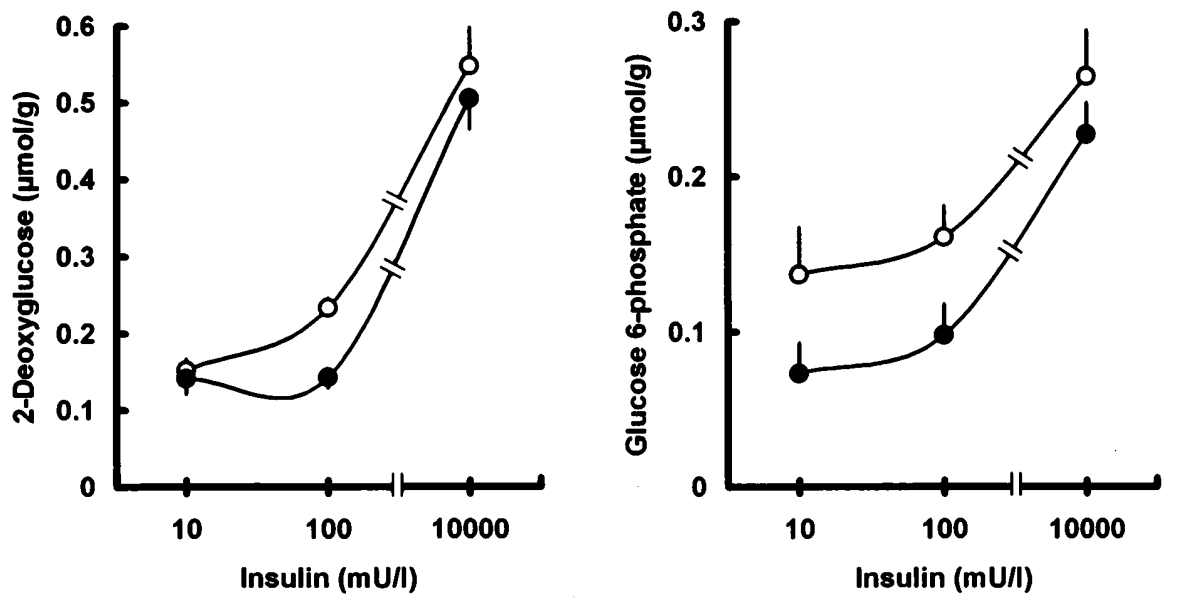

Figure 2 Contents of 2-deoxyglucose and glucose 6-phosphate in rat skeletal muscle at various concentrations of insulin in the presence $(\bullet)$ or absence $(O)$ of furosemide $(0.5 \mathrm{mmol} / \mathrm{l})$. Results are presented as means \pm S.E.M.

2-deoxyglucose phosphorylation was found to be less when furosemide was present $(P<0.02$ and $P<0.05$ respectively). The results were also analyzed by nonpaired Student's $t$-test to establish the concentrations of insulin responsible for the statistically significant differences between the experimental groups of control and furosemide-treated muscles. Furosemide had no statistically significant effect on lactate formation at basal concentrations of insulin ( 1 or $10 \mathrm{mU} / \mathrm{l})$ but markedly decreased these rates at 100,1000 and $10000 \mathrm{mU} / \mathrm{l}$ insulin (Fig. 1).

Furosemide decreased the rate of 3-O-methylglucose transport at $10 \mathrm{mU} / \mathrm{l}$ insulin; however this decrease was not statistically significant (Fig. 1). In contrast, furosemide significantly decreased the rates of 3-O-methylglucose transport at 100 and $10000 \mathrm{mU} / \mathrm{l}$ insulin (Fig. 1). Similarly, the rates of 2-deoxyglucose phosphorylation were significantly decreased at 100 and $10000 \mathrm{mU} / \mathrm{l}$ insulin in the presence of furosemide (Fig. 1). In these experiments, to investigate the effects of furosemide on the sensitivity of glucose transport to insulin, three concentrations of insulin were considered sufficient: a basal concentration, one which is close to the $K_{\mathrm{m}}$ for this muscle preparation and a maximal concentration $(16,19$, 23). The concentration of $10000 \mathrm{mU} / \mathrm{l}$ insulin was used as maximal since higher concentrations of insulin $(100000 \mathrm{mU} / \mathrm{l})$ were shown not to increase further the rate of glucose utilization in the soleus muscle (11).

\section{Discussion}

Diuretics impair glucose tolerance (1-3). Although furosemide is considered to have less impact on glucose homeostasis than thiazide diuretics, several reports suggest that it can deteriorate glycemic control (1-6, 24-26). This may be caused, at least in part, by the development of resistance of peripheral tissues to insulin.
Previous studies have shown that furosemide decreases the rate of glycolysis in rat or rabbit kidney cells or human erythrocytes (27). Skeletal muscle is quantitatively important for glucose utilization in response to insulin (10). In this tissue, insulin increases the rate of glucose utilization mainly by stimulating glucose transport (13). In the present study, the rates of glucose transport and phosphorylation in the soleus muscle preparation were estimated using 3-O-methylglucose and 2-deoxyglucose respectively.

Furosemide decreased the rate of 3-O-methylglucose transport at basal concentrations of insulin; however, this decrease was not statistically significant. In contrast, the rate of 3-O-methylglucose transport was significantly decreased when insulin was elevated. 3-O-Methylglucose is an analog which can be transported through the muscle membrane like glucose but is not further metabolized and, therefore, provides a direct estimate of the rate of glucose transport (28). Thus, the data suggest that, although furosemide may inhibit, to some extent, the basal rate of glucose transport, its main effect is to blunt the insulinstimulated rates of glucose transport (that is, to decrease the sensitivity of glucose transport to insulin) by directly inhibiting the glucose transport process. In skeletal muscle and adipose tissue, glucose is transported via the GLUT1 glucose transporters under basal conditions, while elevation of insulin leads to translocation of GLUT4 glucose transporters from the intracellular pool to the plasma membrane (29). Previous studies in isolated rat adipocytes have shown that furosemide inhibits glucose transport via direct inactivation of the carrier proteins (14). Therefore, the results in the soleus muscle are consistent with a main effect of furosemide to inactivate the GLUT4 glucose transporters after their insulin-stimulated recruitment to the plasma membrane.

Studies using homogenates of skeletal muscle have shown that furosemide, at concentrations higher than those used in this study, inhibits the activity of 
hexokinase and 6-phosphofructokinase (12). If furosemide inhibited hexokinase activity this would lead to an increased level of intracellular glucose which, if sufficient, would increase the rate of glucose efflux and, hence, cause a decrease in the net rate of glucose transport. 2-Deoxyglucose is a glucose analog which can be transported through the muscle membrane and phosphorylated with hexokinase; isolation and measurement of 2-deoxyglucose 6-phosphate, which is trapped within the muscle, provides an excellent estimate of the rate of glucose phosphorylation (28).

In the present study, furosemide decreased the rate of 2-deoxyglucose phosphorylation at physiological and maximal levels of insulin. These changes are similar to those observed in the rate of 3-O-methylglucose transport suggesting that they are dependent upon the effect on the transport process. This view is supported by the findings that lactate formation and 2-deoxyglucose phosphorylation were not significantly decreased at basal levels of insulin. These rates would be expected to decrease if hexokinase was inhibited by furosemide either directly or as a result of a decrease in 6-phosphofructokinase activity. In addition, inhibition of hexokinase and 6-phosphofructokinase would lead to increases in the contents of non-phosphorylated glucose and glucose 6-phosphate. However, neither 2-deoxyglucose nor glucose 6-phosphate were significantly increased at any of the concentrations of insulin studied.

The results of the present study may have clinical significance. Hydrochlorothiazide, a diuretic which has been shown in vivo to induce glucose intolerance $(1,3,5-$ $7,9)$, inhibits glucose transport in rat adipocytes by a mechanism similar to that of furosemide (14). The concentration of furosemide that was used is higher than that observed in the serum of patients receiving the usual therapeutic doses of the drug (5). The selection of this concentration was based on dose-response experiments on the effects of furosemide on hexokinase activity in skeletal muscle homogenates (12) and on previously published experiments on the effects of furosemide on glucose disposal in adipocytes (14). In the latter study which used adipocytes isolated from rats, the effects of furosemide on glucose uptake were shown to be timedependent, progressive and poorly reversible and incubation of adipocytes for $48 \mathrm{~h}$ at concentrations as low as $0.1 \mathrm{mmol} / \mathrm{l}$ furosemide (which are therapeutically attainable) had the same effect as shorter incubations at much higher concentrations of the drug (1.0-6.0 mmol/l) (14). Although there are no data for muscle, progressive accumulation of furosemide in renal tissue has been reported $(30,31)$. It has to be pointed out that, in patients with fluid retention (such as in congestive heart failure) the dosage of furosemide administered can be as high as $320 \mathrm{mg}$ per day (32). It is, therefore, possible that prolonged administration of furosemide in vivo can lead to progressive accumulation of the drug in muscle and impair the sensitivity of glucose utilization to insulin by the mechanisms suggested in the present study.

\section{References}

1 Breckenridge A, Dollery C, Wellborn T \& Fraser R. Glucose tolerance in hypertensive patients on long-term diuretic therapy. Lancet 1967 i $61-64$

2 Wales J, Grant A \& Wolff F. Studies on the hyperglycaemic effects of non-thiazide diuretics. Journal of Pharmacology and Experimental Therapeutics 1968159 229-235.

3 Jones I \& Pickens P. Diabetes mellitus following oral diuretics. Practitioner 1967199 209-210.

4 Furman B. Impairment of glucose tolerance produced by diuretics and other drugs. Pharmacology and Therapeutics 198512 613649.

5 Weiner I. Diuretics and other agents employed in the mobilization of edema fluid. In Goodman and Gillman's The Pharmacological Basis of Therapeutics, edn 8, pp 713-731. Eds T Rall, A Nies \& P Taylor. New York, Oxford, Toronto: Pergamon Press, 1990.

6 Wood A \& Oates J. Adverse reactions to drugs. In Harrison's Principles of Internal Medicine, edn 12, pp 373-379. Eds J Wilson, E Braunwald, K Isselbacher, R Petersdorf, J Martin, A Fauci \& R Root. New York, Toronto: McGraw Hill, 1991.

7 Bressler P \& DeFronzo R. Drugs and diabetes. Diabetes Reviews 19942 53-84.

8 Fajans S, Floyd R, Knopf J, Bull E, Glunsch J \& Conn J. Benzothiazide suppression of insulin release from normal and abnormal islet tissue in man. Journal of Clinical Investigation 1966 41 481-493.

9 Tabachnick I, Gulbenkian B \& Seidman B. The effect of benzothiazides on carbohydrate metabolism. Diabetes 196413 408-418.

10 Baron A, Brechtel G, Wallace P \& Edelman S. Rates and tissue sites of non-insulin and insulin-mediated glucose uptake in humans. American Journal of Physiology 1988255 E769-E774.

11 Dimitriadis G, Leighton B, Parry-Billings M \& Newsholme EA. Effects of the diuretic furosemide on the sensitivity of glycolysis and glycogen synthesis to insulin in the soleus muscle of the rat. Diabetologia 198831 58-61.

12 Dimitriadis G, Tegos C, Golfinopoulou L, Roboti C \& Raptis S. Furosemide-induced hyperglycaemia: the implication of glycolytic kinases. Hormone and Metabolic Research 199325 557-559.

13 Newsholme EA \& Dimitriadis G. Integration of some biochemical and physiological effects of insulin that may play a role in control of blood glucose level. In Diabetes Mellitus, a Fundamental and Clinical Text, pp 263-275. Eds D LeRoith, J Olefsky \& S Taylor. Philadelphia: Lippincott-Raven, 1996.

14 Jacobs D, Mookerjee B \& Jung C. Furosemide inhibits glucose transport in isolated rat adipocytes via direct inactivation of carrier proteins. Journal of Clinical Investigation 198474 16791685.

15 Espinal J, Dohm L \& Newsholme EA. Sensitivity to insulin of glycolysis and glycogen synthesis of isolated soleus muscle strips from sedentary, exercised and exercised-trained rats. Biochemical Journal 1983212 453-458.

16 Challiss RAJ, Espinal J \& Newsholme E. Insulin sensitivity of rates of glycolysis and glycogen synthesis in soleus, stripped soleus, epitrochlearis and hemi-diaphragm muscles isolated from sedentary rats. Bioscience Reports 19833 675-679.

17 Engel P \& Jones J. Causes and elimination of erratic blanks in enzymatic metabolite assays involving the use of $\mathrm{NAD}^{+}$in alkaline hydrazine buffers. Analytical Biochemistry 197888 475-484.

18 Hammerstedt $\mathrm{R}$. A rapid method for isolating glucose metabolites involved in substrate cycling. Analytical Biochemistry $1978 \mathbf{8 8}$ 475-484.

19 Dimitriadis G, Parry-Billings M, Bevan S, Dunger D, Piva T, Krause U, et al. Effects of insulin-like growth factor-I on the rates of glucose transport and utilization in rat skeletal muscle in vitro. Biochemical Journal 1992285 269-274.

20 Dimitriadis G, Parry-Billings M, Leighton B, Piva T, Dunger D, Calder $\mathrm{P}$ et al. Studies on the effects of growth hormone administration in vivo on the rates of glucose transport and utilization 
in rat skeletal muscle. European Journal of Clinical Investigation 199424 161-165.

21 Michal G. Glucose 6-phosphate. In Methods of Enzymatic Analysis pp 191-198. Ed U Bergmeyer. Weinheim: Verlag Chemie, 1984

22 Newsholme E, Leighton B, Challiss J \& Lozeman F. Assessment of biochemical viability of isolated incubated muscle preparations. Biochemical Journal 1986238621.

23 Dimitriadis G, Leighton B, Parry-Billings M, Sasson S, Young M, Krause U et al. Effects of glucocorticoid excess on the sensitivity of glucose transport and metabolism to insulin in rat skeletal muscle. Biochemical Journal 1997321 707-712.

24 Hutcheon D \& Leonard G. Diuretic and anti-hypertensive effects of furosemide. Journal of Clinical Pharmacology 1967 26-33.

25 Lavender S \& McGill R. Nonketotic hyperosmolar coma and furosemide therapy. Diabetes 197423 247-248.

26 Tasker P. Nonketotic diabetic precoma associated with high dose furosemide therapy. British Medical Journal 19761 626-627.

27 Klahr S, Yates J \& Bourgoignie J. Inhibition of glycolysis by ethacrynic acid and furosemide. American Journal of Physiology 1971221 1038-1043.
28 Randle P \& Morgan H. Regulation of glucose uptake by muscle. Vitamins and Hormones 196220 199-249.

29 Gould G \& Holman G. The glucose transporter family: structure, function and tissue-specific expression. Biochemical Journal 1993 295 329-338.

30 Hirsch G, Parkuts A \& Bayne A. Furosemide accumulation by renal tissue. Biochemical Pharmacology 197524 1943-1946.

31 Cohen M, Hirsch E, Vergona R, Ryan J, Kolis S \& Schwartz A. A comparative diuretic and tissue distribution study of bumetamide and furosemide in the dog. Journal of Pharmacology and Experimental Therapeutics 1976197 697-702.

32 Massie B. Cardiac failure. In Current Medical Diagnosis and Treatment, pp 360-368. Eds L Tierney, S McPhee \& M Papadakis. San Francisco: Appleton \& Lange, 1996.

Received 21 October 1997

Accepted 9 March 1998 